\title{
M-Consumer Segmentation: M-Communication, M-Distribution, and M-Accessibility
}

\author{
Ju-Young M. Kang ${ }^{1} \&$ Kim K. P. Johnson ${ }^{2}$ \\ ${ }^{1}$ Apparel Product Design and Merchandising Program, Department of Family and Consumer Sciences, \\ University of Hawaii at Manoa, Honolulu, USA \\ ${ }^{2}$ Retail Merchandising Program, Department of Design, Housing, and Apparel, University of Minnesota, St. \\ Paul, USA \\ Correspondence: Ju-Young M. Kang, Apparel Product Design and Merchandising Program, Department of \\ Family and Consumer Sciences, University of Hawaii at Manoa, Honolulu, USA. Tel: 1-808-956-2244. E-mail: \\ jykang@hawaii.edu
}

Received: September 15, 2012 Accepted: October 5, 2012 Online Published: January 15, 2013

doi:10.5539/ijms.v5n1p86 URL: http://dx.doi.org/10.5539/ijms.v5n1p86

\begin{abstract}
The purpose of this study was to examine the interrelationship among the m-consumers' personality traits, $\mathrm{m}$-communication, $\mathrm{m}$-distribution, and $\mathrm{m}$-accessibility utilities, as well as their willingness to $\mathrm{m}$-shop. This study found that $\mathrm{m}$-communication and $\mathrm{m}$-accessibility utilities were key factors in predicting willingness to $\mathrm{m}$-shop. Our findings demonstrated that more extraverted, more agreeable, and less neurotic m-consumers were likely to perceive high levels of m-communication utility. More conscientious m-consumers were likely to perceive high levels of m-distribution utility and low levels of m-accessibility utility. In addition, this study identified that consumers who were more open to experience, more extraverted, and less conscientious were likely to have high levels of willingness to m-shop. Managerial implications and recommendations for future research were presented.
\end{abstract}

Keywords: M-accessibility, M-communication, M-distribution, mobile web shopping, personality

\section{Introduction}

Often viewed as an extension of e-commerce, mobile commerce is regarded as a distinct channel that conveys ubiquitous value by providing convenience and accessibility at any time and in any place (Balasubramanian, Peterson, \& Jarvenpaa, 2002). In addition to the "anytime" access to services provided by traditional e-commerce, m-commerce allows individuals to accomplish business transactions "anytime and anywhere" (Saidi, 2009). For example, over four million UK consumers access mobile retail websites every month (Ferguson, 2010). The technology research firm Aite Group reported \$3 billion in sales during 2010 for purchases made using a mobile phone, and projected an increase to more than $\$ 27$ billion in 2015 (Mcquire, 2010). The increased use of mobile communication and the swift growth in mobile shopping technologies have considerable financial potential, especially for business-to-consumer retail markets (Lu \& Su, 2009; Saidi, 2009). However, many consumers who have m-shopping experience are unwilling to use mobile devices continuously to do their shopping; as a result, the growth of m-shopping remains relatively slow (Kang, Hung, Yang, \& Hsieh, 2010). What is needed is further empirical knowledge concerning m-consumers' characteristics and $\mathrm{m}$-channel utility.

Research into m-shopping is still in its infancy. Researchers interested in m-commerce have used quantitative approaches to investigate topics such as adoption of m-shopping (Kim, Ma, \& Park, 2009; Ko, Kim, \& Lee, 2009), general attitudes toward m-commerce (Bigné, Ruiz, \& Sanz, 2007), and perceived m-service value (Gummerus \& Pihlstrom, 2011). To develop mobile web shopping in an effective manner, information concerning the type of m-consumer who wants to integrate m-shopping into their consumption behaviors would be useful. With these issues in mind, the purpose of this study was to investigate :(1) whether the Big Five personality traits (i.e., openness to experience, conscientiousness, extraversion, agreeableness, and neuroticism) were related to $\mathrm{m}$-communication, m-distribution, and m-accessibility utilities and ultimately willingness to $\mathrm{m}$-shop, and (2) whether m-communication, m-distribution, and $\mathrm{m}$-accessibility utilities were related to willingness to $\mathrm{m}$-shop. 
In pursuing these objectives, this study has significant managerial and consumer research implications. First, this study contributes to further theoretical understanding of m-consumers' personality traits and perceived m-channel utility, fulfilling an identified gap in the literature. Second, on a managerial level, understanding m-consumers' personality traits is important for m-retailers because personality traits are useful for and have been applied to m-consumer segmentation. The managerial use of personality traits can be used in the segmentation of the marketplace into homogeneous subgroups of m-consumers who have a similar intra-psychic basis for their characteristic needs. Our proposed model may provide a tool for m-retailers to clearly define $\mathrm{m}$-consumer market segments and establish an initial profile of m-consumers, as well as enhance the $\mathrm{m}$-shopping experience for consumers accordingly. Thus, m-retailers can use this information to develop the design of their mobile shopping sites in ways that appeal to m-consumers.

\section{Theoretical Background}

The conceptual foundation for this study was based on Mowen and Spears (1999)'s hierarchical model of personality because the personality traits interact with situations to influence consumer attitudes and actions (Mowen, 2000). The hierarchical model of personality (Mowen \& Spears, 1999) includes three levels: (1) cardinal traits (i.e., genetics and early learning history), (2) central traits (i.e., meditating variables), and (3) surface traits (i.e., individual differences in tendencies to behave within specific situational contexts). In the context of mobile web shopping, we utilized the Big Five personality traits as cardinal traits. We also employed $\mathrm{m}$-communication, $\mathrm{m}$-distribution, and $\mathrm{m}$-accessibility utilities as central traits, and willingness to $\mathrm{m}$-shop as a surface trait.

\section{Hypotheses Development}

\subsection{M-Channel Utilities}

Marketing activities exist by means of various channels (Kotler, 1997). Every marketing function is accomplished through one of three common types of marketing channels: communication channels, transaction channels, and distribution channels (Peterson, Balasubramanian, \& Bronnenberg, 1997). Stewart, Frazier, and Martin (1996) combined marketing functions into two types of channels: communication channels and distribution channels. Further, in the e-commerce context, Li, Kuo, and Russell (1999) identified that a consumer considered a channel to be high in utility if its attributes were perceived to excel in the three dimensions: communication, transaction, and distribution utilities. This study employed these three dimensions of a marketing channel in the mobile web shopping context.

\subsubsection{M-Communication Utility}

The purpose of a communication channel is to fulfill the consumers' information needs for the purpose of decision making (Li et al., 1999). A phased decision making strategy is used when a large number of alternatives exist (Bettman, 1979). These attributes of the communication channel utility consist of a wide selection of goods, updated information, and quality information. Quality information about brands, which refers to correct and up-to-date information, is crucial to consumers' final selections (Li et al., 1999). In the context of mobile web shopping, the m-channel is perceived to be a useful means of communication if it provides a wide selection of goods, as well as updated and quality information.

\subsubsection{M-Distribution Utility}

The function of a distribution channel utility is to mediate the payment for a product and transfer its ownership. The characteristics of a distribution channel include those factors that affect the purchase decision process, from choosing a brand, making payment, and accessing the purchased good, to post-purchase service. In the context of mobile web shopping, the m-channel is perceived as a useful means of distribution if it facilitates the pre-purchase inspection of products, payment security, prompt access to goods purchased, easy exchange and returns, and other post-purchase services.

\subsubsection{M-Accessibility Utility}

Channel accessibility refers to the degree to which time and effort are involved in using a channel (Li et al., 1999). Searching for and identifying information regarding consumers' specific needs has become burdensome and time-consuming as the volume of available information increases. This change encourages consumers to favor communication channels that can customize information without additional consumer effort. Interactivity is one aspect of channel accessibility, and it greatly influences the amount of effort that a user puts forth. Ko et al. (2009) found that instant connectivity was positively associated with the perceived value of mobile web shopping for fashion products. In the context of mobile web shopping, the m-channel is perceived as a useful 
means of distribution if it offers ease of use, a high degree of interactivity, ease of information customization, and convenient access.

Although their findings were not directly related to m-shopping, Li et al. (1999) identified that online shoppers were likely to perceive the web as having higher utilities in communication, distribution, and accessibility than did traditional store-based consumers. Further, frequent online shoppers were likely to perceive higher e-channel utility than did other shoppers who made online purchases only occasionally. These findings lead us to suggest that perceived m-channel utility could help to increase the likelihood that m-consumers would choose to shop by mobile phone. Thus, it is expected that perceived m-channel utilities would be positively related to m-consumers' willingness to $\mathrm{m}$-shop. The following hypotheses were developed:

H1: M-Communication utility is positively related to willingness to m-shop.

H2: M-Distribution utility is positively related to willingness to m-shop.

H3: M-Accessibility utility is positively related to willingness to m-shop.

\subsection{Big Five Personality Traits}

Personality can be defined as the intrinsic organization of an individual's mental world that is stable over time and consistent across different contexts (Piedmont, 1998). Personality trait theories propose that there exist certain patterns and overall consistencies in the ways in which people act; these patterns are described in terms of specific categories of individual differences (Pervin \& John, 1997). McCrae and Costa (1994) stated that a single trait could present itself in different circumstances or situations in life. They noted that personality traits are firm parts of a person's disposition rather than simply habit. Therefore, traits are stable over time and directly affect behavior (Matthews \& Deary, 1998). It is expected that that m-consumers' Big Five personality traits would be related to $\mathrm{m}$-communication, m-distribution, and m-accessibility utilities, as well as to their willingness to m-shop.

\subsubsection{Openness to Experience}

Individuals with greater openness to experiences are likely to be curious about many different things, have broad interests, and be interested in variety (John \& Srivistava, 1999). Further, openness to experience was correlated most strongly with stimulation values and universalism values (Roccas et al., 2002). With regard to specific forms of web usage, a previous study demonstrated that openness to experience was positively associated with using the web for entertainment due to individuals' imaginative natures, and was also associated with using the web for current events due to individuals' curious natures (Tuten \& Bosnjak, 2001). Thus, personality traits such as curiosity, broad interest, imagination, and universalism may allow consumers to perceive m-communication, $\mathrm{m}$-distribution, and m-accessibility utilities. In addition, greater openness to experience had an influence on consumers' willingness to purchase products and services online (Bosnjak et al., 2007). Hence, it is postulated that openness to experience would be positively related to m-communication, m-distribution, m-accessibility utilities, as well as willingness to $\mathrm{m}$-shop.

\subsubsection{Agreeableness}

Agreeableness relates to individuals' interpersonal nature. Higher agreeableness would describe someone who is softhearted, good-natured, trusting, helpful, forgiving, gullible, and straightforward (John \& Srivistava, 1999). Previous researchers found that low degree of agreeableness affected one's affective involvement in online shopping and willingness to purchase products and services online (Bosnjak et al., 2007). Based on these research findings, it is expected that agreeableness would be related to m-communication, m-distribution, $\mathrm{m}$-accessibility utilities, as well as willingness to $\mathrm{m}$-shop. The following hypotheses were developed:

H4-5: Openness to experience (H4) and agreeableness (H5) are positively related to m-communication utility (a), m-distribution utility (b), m-accessibility utility (c), and willingness to m-shop (d).

\subsubsection{Extraversion}

Extraversion refers to the degree to which individuals feel at ease in their relationships with others. Individuals who are extraverted tend to be sociable, lively, vocal, action-oriented, enthusiastic, and more inclined to seek sensory excitement and gratification. Consequently, they value their external images more highly, and they are more receptive to change, and more open to new things and ideas (Costa \& McCrae, 1992). Previous researchers found that extraversion was not related to intention to shop online (Bosnjak et al., 2007) and web usage for entertainment (Tuten \& Bosnjak, 2001). Based on these research findings, it is postulated that extraversion would not be related to $\mathrm{m}$-communication, m-distribution, $\mathrm{m}$-accessibility utilities, or willingness to $\mathrm{m}$-shop. Based on these research findings and reasoning, the following hypothesis was developed: 
H6. Extraversion is not related to m-communication utility (a), m-distribution utility (b), m-accessibility utility (c), or willingness to $\mathrm{m}$-shop (d).

\subsubsection{Conscientiousness}

Conscientiousness is the intensity with which individuals pursue their goals. The more conscientious a person is, the more individualistic, detail-oriented, efficient, responsible, organized, and self-controlled he or she will be (Costa \& McCrae, 1992). Previous researchers found that conscientiousness was not related to intention to shop online (Bosnjak et al., 2007) and any web usage activity (Tuten \& Bosnjak, 2001). Subsequently, Tsao and Chang (2010) identified that conscientiousness did not affect one's hedonic or utilitarian motivation for online shopping. Based on these research findings, it is expected that conscientiousness would be negatively associated with $\mathrm{m}$-communication, $\mathrm{m}$-distribution, and $\mathrm{m}$-accessibility utilities, as well as willingness to $\mathrm{m}$-shop.

\subsubsection{Neuroticism}

Higher neuroticism would describe individuals who tend to feel worried, nervous, emotional, insecure, inadequate, anxious, self-pitying, tense, and unstable (John \& Srivistava, 1999). Even though not directly related to mobile shopping, previous researchers have shown that neurotic individuals minimized web usage for all purposes due to concerns regarding privacy and security when using the web (Tuten \& Bosnjak, 2001). Bosnjak et al. (2007) demonstrated that neuroticism was negatively related to one's intention to shop online. Thus, it is presumed that neuroticism would be negatively associated with m-communication, m-distribution, and $\mathrm{m}$-accessibility utilities, as well as willingness to $\mathrm{m}$-shop. Based on these research findings and this reasoning, the following hypotheses were developed:

H7-8: Conscientiousness (H7) and neuroticism (H8) are negatively related to m-communication utility (a), m-distribution utility (b), m-accessibility utility (c), and willingness to m-shop (d).

\section{Methodology}

\subsection{Sample and Data Collection}

Before data collection for the main survey, a pretest was conducted with college students who are mobile phone users $(n=30)$. For the main survey, data were collected from college students who are mobile phone users. Respondents were approached during classes and asked to volunteer to participate in this research. Volunteers were given a self-administered questionnaire. This process resulted in a purposive sample of 331 individuals.

\subsection{Questionnaire}

The proposed model contained nine constructs. Participants responded to all items using 5-point Likert scales. The measurement of these constructs was developed as follows:

\subsubsection{M-Channel Utilities}

Perceived channel attributes were measured by asking the respondent to rate twelve channel attributes ( $\mathrm{Li}$ et al., 1999) using 5-point Likert scales ranging from not important at all (1) to extremely important (5). The m-channel attributes are as follows: m-communication (e.g., a wide selection of goods, quantity of information, updating of information), m-distribution (e.g., pre-purchase inspection, prompt process to goods purchased, post-purchase service, security of payment methods), and m-accessibility (i.e., effort to use, ease of information customization, convenient access, degree of interactivity). Sample items include "Mobile web shopping provides convenient access" and "Mobile web shopping provides quality information." Reported reliabilities of the scale ranged from $\alpha=.66$ to .84 (Li et al., 1999).

\subsubsection{Personality Traits}

The Big Five Inventory Personality Test (John \& Srivastava, 1999) was employed. This measure requires participants to use 5-point Likert scales ranging from strongly disagree (1) to strongly agree (5). Sample items include "I see myself as someone who tends to find fault with others" and "I see myself as someone who is inventive." Reported reliabilities of the scales ranged from $\alpha=.62$ to .81 (Walczuch \& Lundgren, 2004).

\subsubsection{Willingness to M-Shop}

Items were adopted from Davis (1989) and Lu and Su (2009), using five-point Likert scales ranging from strongly disagree (1) to strongly agree (5). Sample items include "I plan to use my mobile phone to shop for music, games, apparel, or other products in the near future" and "Assuming that I had access to mobile web shopping, I intend to shop using my mobile phone in the near future." The reported reliability of this measure is $\alpha=.81(\mathrm{Lu} \& \mathrm{Su}, 2009)$. 


\section{Results}

\subsection{Participant Characteristics}

A total of 319 responses constituted usable data and participants were women $(50.2 \%)$ and men $(49.8 \%)$. Their ages ranged from 18 to 36 years $(m=21.9)$. With respect to ethnicity, $66.8 \%$ were Caucasian, followed by Asian/Pacific Islander (26.6\%), or Hispanic/Latino (2.5\%). Online shopping experience varied from "once a month or less" (33.2\%), "once every three months or less" (32.9\%), and "once a year or less" (14.7\%). Respondents (33.5\%) had mobile shopping experience purchasing ringtones, applications, tickets, games, music, wallpaper, CDs, shoes, transcripts, books, and sport supplies.

\subsection{Measurement Model Evaluation}

A confirmatory factor analysis was conducted to assess the measurement model. Indicators such as offending estimates, squared multiple correlations, standardized residual covariances, and modification indices were examined to determine whether modification was needed. Table 1 provides final measures, an overview of construct means, standard deviations, and correlations for the measurement model. Convergent validity was supported by the following: (1) all loadings were significant $(p<.001),(2)$ the composite reliability for each construct exceeded the recommended level of .70, and (3) the average variance extracted (AVE) for each construct fulfilled the recommended benchmark of .50 (Hair et al., 1995). As evidence of the discriminant validity of the scales, none of the confidence intervals of the phi estimates included 1.00.

Table 1. Results: measurement model

\begin{tabular}{|c|c|c|c|c|c|c|c|c|c|}
\hline Correlations & 1 & 2 & 3 & 4 & 5 & 6 & 7 & 8 & 9 \\
\hline 1. Openness to Experience & 1.00 & & & & & & & & \\
\hline 2. Extroversion & .32 & 1.00 & & & & & & & \\
\hline 3. Agreeableness & .16 & .20 & 1.00 & & & & & & \\
\hline 4. Conscientiousness & .42 & .20 & .25 & 1.00 & & & & & \\
\hline 5. Neuroticism & .04 & -.01 & -.31 & .02 & 1.00 & & & & \\
\hline 6. M-Communication Utility & .11 & .14 & -.01 & .15 & -.02 & 1.00 & & & \\
\hline 7. M-Distribution Utility & .10 & .07 & .01 & .20 & .04 & .72 & 1.00 & & \\
\hline 8. M-Accessibility Utility & .11 & .09 & -.04 & .10 & .01 & .74 & .73 & 1.00 & \\
\hline 9. Willingness to M-Shop & .23 & .23 & -.11 & .05 & -.01 & .69 & .68 & .71. & 1.00 \\
\hline Mean & 3.83 & 3.56 & 3.93 & 3.81 & 2.93 & 2.64 & 3.35 & 3.21 & 2.74 \\
\hline SD & .85 & .85 & .80 & .82 & .92 & .92 & 1.20 & 1.15 & 1.15 \\
\hline Composite Reliability $^{\mathrm{a}}$ & .74 & .77 & .70 & .70 & .69 & .88 & .92 & .91 & .91 \\
\hline Variance Extracted ${ }^{\mathrm{b}}$ & .52 & .62 & .49 & .51 & .50 & .72 & .73 & .74 & .71 \\
\hline
\end{tabular}

\subsection{Hypotheses Testing}

The path analysis of the causal model, using structural equation analysis, was conducted by the method of maximum-likelihood estimation procedure. Our model exhibited a good fit with the data $\left(\chi^{2}=431.59\right.$ with $219 \mathrm{df}$, $\chi^{2} / d f=1.97, \mathrm{CFI}=.98, \mathrm{GFI}=.97, \mathrm{NNFI}=.98, \mathrm{RMSEA}=.049$, and $\left.\mathrm{SRMR}=.042\right)$. Regarding H1 -3 , m-communication utility $(\beta=.67, t=7.85)$ and $\mathrm{m}$-accessibility utility $(\beta=.30, t=3.31)$ were found to be the most significant predictors of willingness to m-shop $(p<.001)$, followed by m-distribution utility $(\beta=-.24, t=$ $-2.08, p<.05)$. Interestingly, $\mathrm{m}$-distribution utility was negatively related to willingness to $\mathrm{m}$-shop.

In terms of the five personality traits, for H4-8, openness to experience was positively related to willingness to $\mathrm{m}$-shop $(\beta=.15, t=3.73, p<.001)$. Extraversion was positively related to m-communication utility $(\beta=.08, t=$ $3.02, p<.05)$ and willingness to $\mathrm{m}$-shop $(\beta=.10, t=2.37, p<.05)$. Conscientiousness was positively related to m-distribution utility $(\beta=.13, t=2.14, p<.05)$, m-accessibility utility $(\beta=-.09, t=-3.42, p<.01)$, and willingness to $\mathrm{m}$-shop $(\beta=-.11, t=-2.57, p<.05)$. Neuroticism was negatively related to $\mathrm{m}$-communication utility $(\beta=-.06, t=-2.42, p<.05)$. Agreeableness was positively related to m-communication utility $(\beta=.06, t=$ $2.31, p<.05)$. Additionally, we found $\mathrm{m}$-distribution utility had a significant effect on m-accessibility utility $(\beta$ $=.67, t=7.83, p<.001)$ and $\mathrm{m}$-communication utility $(\beta=.66, t=7.19, p<.001)$ (see Table 2 and Figure 1$)$. 
Table 2. Results: structural model

\begin{tabular}{|c|c|c|c|}
\hline \multicolumn{2}{|c|}{ Endogenous Constructs } & $\mathrm{SE}^{\mathrm{a}}$ & $\mathrm{t}$-value ${ }^{\mathrm{b}}$ \\
\hline \multicolumn{4}{|c|}{ Willingness to $\mathrm{M}$-Shop $\left(\mathrm{R}^{2}=.54\right)$} \\
\hline H1 & M-Communication Utility & .67 & $7.85^{* * *}$ \\
\hline $\mathrm{H} 2$ & M-Distribution Utility & -.24 & $-2.08 *$ \\
\hline H3 & M-Accessibility Utility & .30 & $3.31 *$ \\
\hline $\mathrm{H} 4 \mathrm{~d}$ & Openness to Experience & .15 & $3.73^{* * *}$ \\
\hline $\mathrm{H} 5 \mathrm{~d}$ & Extraversion & .10 & $2.37^{*}$ \\
\hline H6d & Agreeableness & .01 & .23 \\
\hline $\mathrm{H} 7 \mathrm{~d}$ & Conscientiousness & -.11 & $-2.57 *$ \\
\hline $\mathrm{H} 8 \mathrm{~d}$ & Neuroticism & .03 & .82 \\
\hline \multicolumn{4}{|c|}{ M-Communication Utility $\left(\mathrm{R}^{2}=.60\right)$} \\
\hline $\mathrm{H} 4 \mathrm{a}$ & Openness to Experience & .01 & .15 \\
\hline $\mathrm{H} 5 \mathrm{a}$ & Extraversion & .08 & $3.02 *$ \\
\hline H6a & Agreeableness & .06 & $2.31 *$ \\
\hline $\mathrm{H} 7 \mathrm{a}$ & Conscientiousness & -.04 & -1.51 \\
\hline $\mathrm{H} 8 \mathrm{a}$ & Neuroticism & -.06 & $-2.42 *$ \\
\hline \multicolumn{4}{|c|}{ M-Distribution Utility $\left(\mathrm{R}^{2}=.12\right)$} \\
\hline $\mathrm{H} 4 \mathrm{~b}$ & Openness to Experience & .05 & .80 \\
\hline $\mathrm{H} 5 \mathrm{~b}$ & Extraversion & -.02 & -.33 \\
\hline H6b & Agreeableness & .04 & .69 \\
\hline $\mathrm{H} 7 \mathrm{~b}$ & Conscientiousness & .13 & $2.14 *$ \\
\hline $\mathrm{H} 8 \mathrm{~b}$ & Neuroticism & -.01 & -.19 \\
\hline \multicolumn{4}{|c|}{ M-Accessibility Utility $\left(\mathrm{R}^{2}=.61\right)$} \\
\hline $\mathrm{H} 4 \mathrm{c}$ & Openness to Experience & .01 & .01 \\
\hline $\mathrm{H} 5 \mathrm{c}$ & Extraversion & .05 & 1.92 \\
\hline H6c & Agreeableness & .03 & 1.30 \\
\hline $\mathrm{H} 7 \mathrm{c}$ & Conscientiousness & -.09 & $-3.42 * *$ \\
\hline $\mathrm{H} 8 \mathrm{c}$ & Neuroticism & -.04 & -1.7 \\
\hline \multicolumn{4}{|c|}{ Fit Statistics } \\
\hline \multicolumn{2}{|c|}{$\mathrm{N}$} & 319 & \\
\hline \multicolumn{2}{|c|}{$\chi^{2}(d f)$} & $431.59(219)$ & \\
\hline \multicolumn{2}{|c|}{$\chi^{2} / d f$} & 1.97 & \\
\hline \multicolumn{2}{|c|}{ CFI } & .98 & \\
\hline \multicolumn{2}{|c|}{ NNFI } & .98 & \\
\hline \multirow{2}{*}{\multicolumn{2}{|c|}{$\begin{array}{l}\text { RMSEA } \\
\text { SRMR }\end{array}$}} & .049 & \\
\hline & & .042 & \\
\hline
\end{tabular}

${ }^{a}$ SE, Standardized estimate

$\mathrm{b} * p<.05, * * p<.01, * * * p<.001$ 


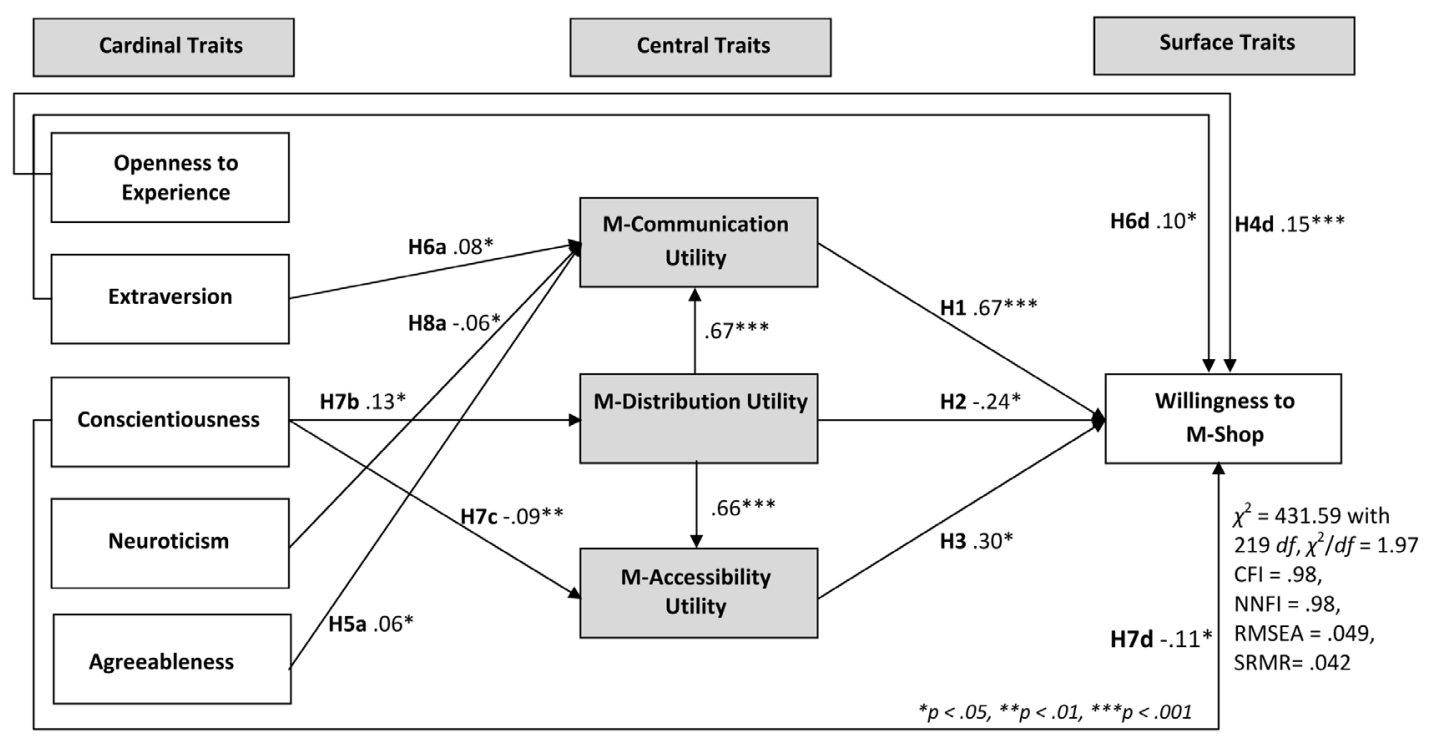

Figure 1. Final model

\subsection{Indirect Effects}

The indirect effects of the five exogenous constructs (i.e., personality traits) on willingness to $\mathrm{m}$-shop were also assessed. The Sobel (1982) test was used to calculate for mediation in the structural model. Applied to our research, the Sobel test assessed whether a mediator variable (m-communication, m-distribution, m-accessibility utilities) significantly carries the effect of independent variables (i.e., personality traits) to a dependent variable (i.e., willingness to $\mathrm{m}$-shop). Extraversion $\left(\beta_{\text {indirect }}=.05, z=1.80, p<.05\right)$ had a significant indirect effect on willingness to $\mathrm{m}$-shop via $\mathrm{m}$-communication utility. Since the direct relationship between extraversion and willingness to $\mathrm{m}$-shop was significant, m-communication utility could be regarded as a partial mediator in the link between extraversion and willingness to $\mathrm{m}$-shop. Other exogenous constructs did not have a significant indirect effect on willingness to $\mathrm{m}$-shop via $\mathrm{m}$-communication, $\mathrm{m}$-distribution, and $\mathrm{m}$-accessibility utilities.

\section{Discussion and Managerial Implications}

The purpose of this study was to examine the interrelationship among the m-consumers' personality traits, $\mathrm{m}$-communication, m-distribution, and m-accessibility utilities, as well as their willingness to m-shop. Our results not only verify theoretical conceptions regarding personality traits and their effects on m-channel utilities and willingness to $\mathrm{m}$-shop, but also provide insights into the implementation and development of $\mathrm{m}$-shopping services. Furthermore, the results aid in the segmentation of m-consumers.

M-communication and $\mathrm{m}$-accessibility utilitieswere key factors in predicting willingness to $\mathrm{m}$-shop. M-distribution utility was positively related to m-communication and m-accessibility utilities. Interestingly, contrary to our hypothesis, m-distribution utility was negatively associated with willingness to m-shop. In other words, m-consumers who perceivedlow levels of m-distribution utility were likely to be willing to $\mathrm{m}$-shop. It appears that consumers who are willing to m-shop may accept and not seriously consider the disadvantages of m-distribution utility (i.e., pre-purchase inspection, a secure means of payment) due to the well-known drawbacks of the mobile web shopping format.

From the managerial perspective, to enhance the m-shopping web's m-communication utility, our findings suggest that $\mathrm{m}$-retailers and $\mathrm{m}$-service providers need to provide a broader assortment of $\mathrm{m}$-merchandise, along with up-to-date and quality information that satisfies m-shoppers' specific needs. Limited previews could facilitate trial and possibly purchase. Pinch-and-zoom views of retail product images, allowing for close product examination, could enhance m-consumers' decision-making abilities. Further, there is a need for enhancement with regard to the search and navigation functions, as well as monetary transaction systems and security. To intensify m-accessibility utility, m-retailers need to raise the degree of interactivity, provide convenient access, and make customized-information more available by improving mobile web functions. Fast download speeds as well as stable Internet connectivity need to be improved. 
Our findings demonstrated that more extraverted, more agreeable, and less neurotic m-consumers were likely to perceive high levels of m-communication utility. More conscientious $\mathrm{m}$-consumers were likely to perceive high levels of m-distribution utility and low levels of m-accessibility utility. In addition, this study identified that consumers who were more open to experience, more extraverted, and less conscientious were likely to have high levels of willingness to m-shop. Our findings are consistent with previous work (Bosnjak et al., 2007), which highlighted the fact that willingness to purchase products and services online was positively affected by one's openness to experience and was negatively affected by conscientiousness (Bosnjak et al., 2007). Contrary to the hypothesis, extraversion was positively related to willingness to $\mathrm{m}$-shop. Extraverts tend to be impulsive and activity-seeking, and to yearn for sensory excitement; perhaps this tendency may affect their shopping activity on the mobile web. However, our finding is consistent with that of previous researchers, who demonstrated that the degree of environmental stimulation that individuals desired positively influenced their m-commerce intentions (Mahatanankoon, 2007).

Collectively, our results suggest that m-retailers need to fulfill m-consumers' tendencies, including their interest in variety, sociability, and desire for sensory excitement, by offering diverse mobile web functions and promotions. For instance, m-retailers could utilizediverse sales promotions, blogs featuringsocial shopping experiences, and YouTube. In particular, $\mathrm{m}$-practitioners and $\mathrm{m}$-retailers could provide $\mathrm{m}$-coupons, m-loyalty programs, and pop-up m-stores focusing on special events/incentives and excitement-building programs. M-practitioners and m-retailers could link coupons directly to their loyalty programs. Online pop-up stores refer to fleeting storefronts that are active for a limited time only, and usually center on a new product or limited range of products provided by a retailer (Biggs, 2012). For instance, Neiman Marcus and Saks send e-mail notifications of limited-time events to registered customers, announcing a three-hour sale of premium-brand products at half price. These retailers mitigate the possibility of developing a reputation for cheap products or clearance sales by offering huge discounts to select customers only, and for short periods only. M-practitioners and $\mathrm{m}$-retailers could make limited-time offers to registered $\mathrm{m}$-consumers, and could send e-mail notifications or $\mathrm{m}$-text messages to their regular/loyal m-consumers to satisfy theirdesire for varietyand sensory excitement. As part of an overall communication strategy, a well-received blog could communicate trends and product recommendations/reviews, announce special events, and create word-of-mouth interest, which relates to communication among individuals about a particular retailer (Van Hoye \& Lievens, 2007). In addition, YouTube could provide an effective medium for introducing new merchandise videos and special events. Thus, an understanding of the behavioral spectrum of different $\mathrm{m}$-consumer personalities and $\mathrm{m}$-channel utilities could help in the formulation of m-consumer market segments and successful m-marketing activities that are better targeted and more effective.

\section{Limitations and Future Research}

One direction for future research is to test our model using a representative sample of consumers reflecting diverse demographic and cultural factors. Our findings were obtained at one point in time and reflect cross-sectional data. A longitudinal study would facilitate a better understanding of the interrelationships among proposed variables as m-channel utilitiesand responses change over time. Particularly, keeping track of shifts in m-shopping experience, examining m-consumers' perceptions, m-channel utility, and m-loyalty after one year and again after two years of using of the mobile web for shopping would provide better empirical evidence. Additionally, m-consumers' positive word-of-mouth may be a very important marketing strategy for the rapid diffusion of m-shopping services. Researchers might examine the effect of positive electronic word-of-mouth on actual $\mathrm{m}$-shopping behavior, satisfaction, and m-loyalty.

\section{References}

Balasubramanian, S., Peterson, R. A., \& Jarvenpaa, S. L. (2002). Exploring the implications of m-commerce for markets and marketing. Journal of the Academy of Marketing Science, 30(4), 348-361. http://dx.doi.org/10.1177/009207002236910

Bettman, J. R. (1979). Memory factors in consumer choice: A review. The Journal of Marketing, 43(Spring), 37-53. http://dx.doi.org/10.2307/1250740

Biggs, J. (2012). Bonobos launches "Cyber Pop-up Store," further blurring the lines of ecommerce. Retrieved from http://techcrunch.com/2012/03/21/bonobos-launches-cyber-pop-up-store-further-blurring-the-lines-of-ecom merce/

Bigné, E., Ruiz, C., \& Sanz, S. (2007). Key drivers of mobile commerce adoption an exploratory study of Spanish mobile users. Journal of Theoretical and Applied Electronic Commerce Research, 2(2), 48-60. 
Bosnjak, M., Galesic, M., \& Tuten, T. (2007). Personality determinants of online shopping: Explaining online purchase intentions using a hierarchical approach. Journal of Business Research, 60(6), 597-605. http://dx.doi.org/10.1016/j.jbusres.2006.06.008

Costa, P. T., \& McCrae, R. R. (1992). NEO PI-R Professional manual: Revised NEO Personality Inventory (NEO PI-R) and NEO-Five Inventory (FFI). Lutz, FL: Psychological Assessment Resources.

Davis, F. D. (1989). Perceived usefulness, perceived ease of use, and user acceptance of information technology. MIS Quarterly, 13(3), 319-340. http://dx.doi.org/10.2307/249008

Ferguson, T. (2010). Shopping on your smartphone: Retailers ramp up app plans. zdnet.com. Retrieved from http://www.zdnet.com/shopping-on-your-smartphone-retailers-ramp-up-app-plans-3040153701/

Gummerus, J., \& Pihlstrom, M. (2011). Context and mobile services' value-in-use.Journal of Retailing and Consumer Services, 18(6), 521-533. http://dx.doi.org/10.1016/j.jretconser.2011.07.002

Hair, J. F., Anderson, R. E., Tatham, R. L., \& Black, W. C. (1995). Multivariate data analysis (4th ed.). Englewood Cliffs, NJ: Prentice Hall.

John, O. P., \& Srivastava, S. (1999). The Big-Five Trait taxonomy: History, measurement, and theoretical perspectives. In L. A. Pervin, \& O. P. John (Eds.), Handbook of personality: Theory and research (2nd ed., pp.102-139). New York: Guilford Press.

Kang, C., Hung, M., Yang, S., Hsieh, T., \& Tang, S. (2010). Factors affecting the continued intention of mobile shopping. Proceedings of the Industrial Engineering and Engineering Management, IEEE International Conference. http://dx.doi.org/10.1109/IEEM.2010.5674612

Kim, J., Ma, Y. J., \& Park, J. (2009). Are US consumers ready to adopt mobile technology for fashion goods?: An integrated theoretical approach. Journal of Fashion Marketing and Management, 13(2), 215-230. http://dx.doi.org/10.1108/13612020910957725

Ko, E., Kim, E. Y., \& Lee, E. K. (2009). Modeling consumer adoption of mobile shopping for fashion products in Korea. Psychology and Marketing, 26(7), 669-687. http://dx.doi.org/10.1002/mar.20294

Kotler, P. (1997). Marketing management: Analysis, planning, implementation and control (9th ed.). Englewood Cliffs, NJ: Prentice Hall.

Li, H., Kuo, C., \& Russell, M. G. (1999). The impact of perceived channel utilities, shopping orientations, and demographics on the consumer's online buying behavior. Journal of Computer-Mediated Communication, 5(2). http://dx.doi.org/10.1111/j.1083-6101.1999.tb00336.x

Lu, H. P., \& Su, P. Y. J. (2009). Factors affecting purchase intention on mobile shopping websites. Internet Research, 19(4), 442-458. http://dx.doi.org/10.1108/10662240910981399

Mahatanankoon, P. (2007). The effects of personality traits and optimum stimulation level on text-messaging activities and m-commerce intention. International Journal of Electronic Commerce, 12(1), 7-30. http://dx.doi.org/10.2753/JEC1086-4415120101

Matthews, G., \& Deary, I. J. (1998). Personality traits. New York: Cambridge University Press.

McCrae, R. R., \& Costa Jr, P. T. (1994). The stability of personality: Observations and evaluations. Current Directions in Psychological Science, 3(6), 173-175. http://dx.doi.org/10.1111/1467-8721.ep10770693

McGuire, K. (2010). Shoppers hunt bargains via their smart phones. Star Tribune. Retrieved from http://www.startribune.com/lifestyle/yourmoney/110882094.html?elr=KArksUUUoDEy3LGDiO7aiU

Mowen, J. C., \& Spears, N. (1999). A hierarchical approach to understanding compulsive buying among college students. Journal of Consumer Psychology, 8(4), 407-430. http://dx.doi.org/10.1207/s15327663jcp0804_03

Pervin, L. A., \& John, O. P. (1997). Personality: Theory and research (7th ed.). Oxford: John Wiley and Sons.

Peterson, R. A., Balasubramanian, S., \& Bronnenberg, B. J. (1997). Exploring the implications of the Internet for consumer marketing. Journal of the Academy of Marketing Science, 25(4), 329-346. http://dx.doi.org/10.1177/0092070397254005

Piedmont, R. L. (1998). The revised NEO personality inventory: Clinical and research applications. New York, NY: Plenum Pub Corp.

Roccas, S., Sagiv, L., Schwartz, S. H., \& Knafo, A. (2002). The big five personality factors and personal values. Personality and Social Psychology Bulletin, 28(6), 789-801. http://dx.doi.org/10.1177/0146167202289008 
Saidi, E. (2009). Mobile opportunities, mobile problems: Assessing mobile commerce implementation issues in Malawi. Journal of Internet Banking and Commerce, 14(1), 1-10. Retrieved from http://www.arraydev.com/commerce/jibc/

Sobel, M. E. (1982). Asymptotic confidence intervals for indirect effects in structural equation models. In S. Leinhardt (Ed.), Sociological methodology 1982 (pp. 290-312). Washington DC: American Sociological Association.

Stewart, D. W., Frazier, G. L., \& Martin, I. (1996). Integrated channel management: Mergingthe communication and distribution functions of the firm. In E. Thorson, \& J. More (Eds.), Integratedcommunication: Synergy of persuasive voices (pp.185-215). Mahwah, NJ: Lawrence Erlbaum Associates.

Tsao, W., \& Chang, H. (2010). Exploring the impact of personality traits on online shopping behavior. African Journal of Business Management, 4(9), 1800-1812. Retrieved from http://www.academicjournals.org/AJBM

Tuten, T. L., \& Bosnjak, M. (2001). Understanding differences in web usage: The role of need for cognition and the five factor model of personality. Social Behavior and Personality, 29(4), 391-398. http://psycnet.apa.org/doi/10.2224/sbp.2001.29.4.391

Van Hoye, G., \& Lievens, F. (2007). Social influences on organizational attractiveness: Investigating if and when word of mouth matters. Journal of Applied Social Psychology, 37(9), 2024-2047. http://dx.doi.org/10.1111/j.1559-1816.2007.00249.x

Walczuch, R., \& Lundgren, H. (2004). Psychological antecedents of institution-based consumer trust in e-retailing. Information \& Management, 42(1), 159-177. http://dx.doi.org/10.1016/j.im.2003.12.00 